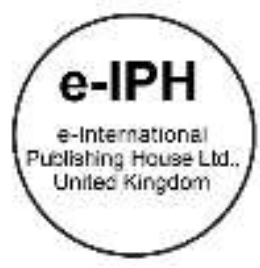

\title{
Perception of Soft Contact Lens Usage among Health Sciences and Business Management Students
}

\author{
Nur Aresya Ahmad Najmee ${ }^{1}$, Nur Fazliana Abu Hassan 1, Nurulain Muhamad ${ }^{1}$, Noor Haziq Saliman 2,3 \\ 1 Optometry, Faculty of Health Sciences, \\ Universiti Teknologi MARA Cawangan Selangor, 42300 Bandar Puncak Alam, Selangor, Malaysia. \\ 2 Institute of Inflammation and Ageing, University of Birmingham, United Kingdom. \\ ${ }_{3}^{3}$ National Institute for Health-Research Surgical Reconstruction and Microbiology Research Centre (NIHR-SRMRC), \\ University Hospitals Birmingham NHS Foundation Trust, Birmingham, United Kingdom
}

aresyanajmee@uitm.edu.my, nurfazliana.abuhassan@gmail.com, nurulain5510@uitm.edu.my, N.H.BinSaliman@bham.ac.uk

Tel: +60179450024

\begin{abstract}
The knowledge and awareness on contact lens care can enhance the positive attitude of the wearers and reduce related complications. This study aimed to investigate the perceptions of contact lens use and care of university students with different backgrounds. A questionnaire regarding the perception and practice of contact lens use was online distributed. The perception of contact lens use as an optical device between spectacle and contact lens was statistically significant $(p<0.05)$. However, there was no significant difference between the perception and awareness of two groups $(p>0.05)$. Regardless of educational field background, all contact lens wearers have the same behavioural assessment of contact lens awareness.
\end{abstract}

Keywords: behaviour, contact lens usage, knowledge, awareness.

eISSN: 2398-42870 2021. The Authors. Published for AMER ABRA cE-Bs by e-International Publishing House, Ltd., UK. This is an open access article under the CC BYNCND license (http://creativecommons.org/licenses/by-nc-nd/4.0/). Peer-review under responsibility of AMER (Association of Malaysian Environment-Behaviour Researchers), ABRA (Association of Behavioural Researchers on Asians/Africans/Arabians) and cE-Bs (Centre for Environment-Behaviour Studies), Faculty of Architecture, Planning \& Surveying, Universiti Teknologi MARA, Malaysia.

DOI: https://doi.org/10.21834/ebpj.v6i18.3058

\subsection{Introduction}

Contact lenses are temporary prostheses worn on the eyes for optical, cosmetic, or therapeutic reasons. In Malaysia, it is becoming increasingly significant as an optical corrective device. Around 150 million individuals worldwide wear contact lenses, with the younger population. Notably, university students and working adults are the most prevalent wearers (Stapleton et al., 2017). Soft contact lens prescriptions accounted for more than $90 \%$ of all prescriptions worldwide. Among university students, the prevalence of contact lens wearers is $40.5 \%$, with most wearers, $80.2 \%$, using soft contact lenses (Ibrahim et al., 2018). Soft contact lens is preferable for vision correction as it is made up of water and it is more stable due to its size and slightest movement. Besides, the adaption time for soft contact lenses is shorter, thus increasing initial comfort faster in the first-time wearer (Jones et al., 2013). Furthermore, the soft contact lens does not deform the cornea easily; hence, it will not affect the corneal (Çavdarlı, \& Topçu-Yılmaz, 2018). It is also accounts for cosmetic purpose and refractive correction such as myopia and astigmatism. Nonetheless, the functions of soft contact lens should linearly equivalent with the knowledge and awareness of the contact lens use and care. The awareness and education regarding contact lens care can enhance a positive attitude among young wearers (V.Kumar, 2013). Moreover, proper hygiene and lens care maintenance is essential to control

eISSN: 2398-4287@ 2021. The Authors. Published for AMER ABRA cE-Bs by e-International Publishing House, Ltd., UK. This is an open access article under the CC BYNCND license (http://creativecommons. org/licenses/by-nc-nd/4.0/). Peer-review under responsibility of AMER (Association of Malaysian Environment-Behaviour Researchers), ABRA (Association of Behavioural Researchers on Asians/Africans/Arabians) and CE-Bs (Centre for Environment-Behaviour Studies), Faculty of Architecture, Planning \& Surveying, Universiti Teknologi MARA, Malaysia.

DOI: https://doi.org/10.21834/ebpj.v6i18.3058 
and reduce the related complications. Thus, this cross-sectional survey investigates and compares the perceptions of contact lens use and care among university students from different educational backgrounds.

\subsection{Literature review}

Awareness about contact lenses is critical for accurate perception and healthy practice among contact lens users. It includes the knowledge of contact lenses, benefits to the wearer, and associated complications. Knowledge of contact lens use is fundamental, including the availability of different types of contact lenses on the market, the use of each contact lens, the care and maintenance, and the contact lens complications. A study revealed that majority of which $95.8 \%$ of students had some knowledge of contact lenses while only the other $4.2 \%$ of the surveyed students were ignorant of contact lens usage (Tchiakpe et al., 2017). Contrary to the finding, a separate study revealed that most students lacked proper knowledge of contact lens use (Neyaz et al., 2017). It shows that the evidence for this relationship is still inconclusive. Despite the participants' awareness of contact lens use, only $35 \%$ knew some benefits.

In comparison, the remaining $65 \%$ admitted to being unaware of the benefits of contact lens use (Tchiakpe et al., 2017). Contact lens use has several advantages, including widening the field of vision and reducing spherical aberration, chromatic aberration, and distortions (Şengör et al., 2018). Ocular health education, including proper contact lens wear practices, is crucial in preventing complications caused by the wearer's inappropriate behaviour (Tajunisah et al., 2008). The perception and the wearer's behaviour are essential in controlling the ocular complications. One of the ways of investigating this is from the person's perception regarding their knowledge of contact lens use. The prevalence of contact lens-related complications increases as there is an increase in contact lens wearers. It is reported that $57 \%$ of the contact lens wearer present to contact lens clinics (Gyawali et al., 2014). The most common contact lenses related to ocular complications are lens-related corneal ulcers as well as allergic reactions to either the lens or the contact lens cleaning solutions. Corneal ulcers are mainly caused by a bacterial infection, pseudomonas aeruginosa and protozoal infection acanthamoeba castellani (Neyaz et al., 2017). However, literatures show that only a minority of people are aware of the potential risks associated with contact lens use. Approximately $63.3 \%$ of students had only a superficial understanding of the potential complications of contact lens use (Tchiakpe et al., 2017). On another note, $84 \%$ of the participants had no knowledge of contact lens complications, as a higher level of awareness is associated with education (V.Kumar, 2013).

Furthermore, the primary motivation for participants to learn about contact lenses and improve their awareness is their personal experience. Fortunately, most contact lens wearer knows contact lens use. Sufficient knowledge about the contact lens was demonstrated by $71.7 \%$ of the participants. This finding shows that personal experience and the educational institution significantly influenced contact lens knowledge. However, the increase in contact lens wearers leads to an increased of contact lens complications. $60 \%$ of participants reported that the contact lens is unsuitable for persons with bad hygiene and poor motivation (Among et al., 2019). Poor hygiene among contact lens wearers was reported to cause severe microbial contamination, which may be asymptomatic or may lead to serious eye infections, including pseudomonas aeruginosa and staphylococcus aureus. A study has found that $80 \%$ of contact lens complications are related to improper maintenance (Kumar et al., 2017). Thus, proper contact lens perceptions among contact lens wearers play a significant role in avoiding contact lens complications. In addition to that, $41 \%$ of the contact lens wearer had no idea about the necessity to change their contact lenses based on a set schedule (Zhu et al., 2018). These problems later can lead to further contact lens-related complications. Education on the various alternatives to allay fears on the contact lens complications could enhance awareness and create a more positive attitude towards contact lens use (Ayanniyi et al., 2014). To date, studies on the perceptions and awareness of contact lens use do not have concrete conclusions about how various educational backgrounds influence these two factors differently.

\subsection{Method}

This study has been approved by the Research Ethics Committee of Universiti Teknologi Mara (600-TNCPI (5/1/6). It was a cross-sectional survey that used purposive sampling via a self-administrative questionnaire through an online platform. The data of the spectacle wearers from Bussiness Management and Health Sciences students were gathered from UiTM Vision Care Clinics. From the population of 224 students, Raosoft software has calculated the total sampling of 142 participants to $95 \%$ of the confidence interval, $5 \%$ margin error, and $50 \%$ of the response distribution. The participants were recruited based on the inclusion and exclusion criteria. The participants were the spectacle and contact lens wearers, aged 19-26 years old. The refractive powers for the participants were between +3.00DS to -6.00DS with the visual acuity of $6 / 6$ and had no history of systemic and ocular diseases. Participants were also free from any allergies and surgeries. The history taking and the consent form were obtained prior to the study. A questionnaire regarding the perception and practice of contact lens use was modified and adopted from (Şengör et al., 2018) was used in this study to ascertain the perceptions and practices of contact lens wearers among spectacle and contact lens wearers. The questionnaire was divided into two parts, A and B, with 27 contact lensrelated questions regarding the perceptions of contact lens use and awareness. This section inquired about the variables that impact participants' opinions of contact lens awareness, including the motivations for using contact lenses and their knowledge about contact lenses and contact lens complications. The score ranged from 1 to 5 (1=strongly disagree, 2=disagree, 3=neutral, 4=agree, 5=strongly agree). The completed questionnaire was analyzed using the Statistical Package for Social Sciences (SPSS) version 20.

\subsection{Results}

The independent T-test was used to compare the perceptions of contact lens use as an optical device between spectacle and contact lenses wearers. The independent T-test was also employed to compare the perceptions of contact lens use between health sciences and 
business management students. All the participants were students between the ages of 20 to 25 years old. $52.1 \%$ of all participants were health sciences, students, while the remaining $47.9 \%$ were business management students. Figure 1 depicts the participants' percentage based on the optical devices used ( $45.1 \%$ of spectacle wearers and $54.9 \%$ of contact lenses wearers).

\section{Optical devices}

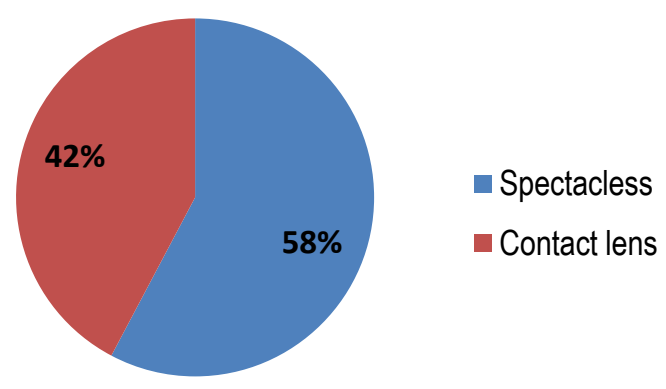

Figure 1 The distribution of optical devices used among participants

\subsection{Perception of contact lens use as an optical device}

Three variables were studied that impacted the perceptions of contact lens usage as an optical instrument among spectacle and contact lens wearers. These were perceptions in generals, costs, and complications. According to the findings in Table 1, generally, both spectacle and contact lens wearers believed that wearing glasses was more convenient than wearing contact lens. In terms of costs, spectacle wearers agreed that the contact lens was more expensive, while contact lens wearers had a neutral attitude. Regarding the contact lens complications, the biggest concern among spectacle wearers was the risk of eye infections $(4.45 \pm 0.71)$, whereas contact lens wearers were more concerned about discomfort and dryness (3.57 \pm 1.24$)$. Both groups' perception of spectacle and contact lens wearers were differed significantly (Table 2). Contact lens complications significantly impacted perceptions of contact lens usage among the three variables studied, followed by the perception in general and costs.

\begin{tabular}{|c|c|c|}
\hline \multirow[t]{2}{*}{ Statements } & $\begin{array}{c}\text { Spectacles } \\
(n=82)\end{array}$ & $\begin{array}{c}\text { Contact Lens } \\
(n=60)\end{array}$ \\
\hline & Mean \pm SD & Mean \pm SD \\
\hline \multicolumn{3}{|l|}{ Perceptions in general } \\
\hline I think using a contact lens is difficult. & $3.95 \pm 1.08$ & $2.42 \pm 1.15$ \\
\hline I think using spectacles is comfortable. & $3.93 \pm 0.97$ & $3.33 \pm 1.40$ \\
\hline I think using contact lenses is harmful to the eye. & $3.89 \pm 0.89$ & $2.82 \pm 1.07$ \\
\hline \multicolumn{3}{|l|}{ Perceptions on cost } \\
\hline I think contact lenses are expensive. & $3.78 \pm 0.88$ & $3.10 \pm 1.16$ \\
\hline \multicolumn{3}{|l|}{ Perceptions of complications } \\
\hline I am afraid contact lens can affect near vision. & $3.74 \pm 1.04$ & $2.80 \pm 1.26$ \\
\hline I am afraid contact lens can increase refractive error. & $3.78 \pm 0.99$ & $2.82 \pm 1.08$ \\
\hline I am afraid contact lens can lead to infections. & $4.45 \pm 0.71$ & $3.50 \pm 1.23$ \\
\hline I am afraid the contact lens will cause itchy eyes. & $4.44 \pm 0.70$ & $3.55 \pm 1.21$ \\
\hline I am afraid if I wear contact lens, the lens will stick to my eye. & $3.98 \pm 1.13$ & $2.90 \pm 1.35$ \\
\hline I am afraid of stinging and burning effects in my eyes if I wear contact lenses. & $4.27 \pm 0.77$ & $3.13 \pm 1.21$ \\
\hline I am afraid of redness in my eyes if I wear contact lenses. & $4.29 \pm 0.78$ & $3.42 \pm 1.24$ \\
\hline I am afraid of ocular surface scratches if I wear contact lenses. & $4.12 \pm 0.94$ & $3.25 \pm 1.25$ \\
\hline I am afraid of the presence of excessive discharge when wearing contact lens. & $4.12 \pm 0.96$ & $3.10 \pm 1.23$ \\
\hline I am afraid of evening discomfort and dryness when wearing contact lens. & $4.41 \pm 0.67$ & $3.57 \pm 1.24$ \\
\hline I am afraid of vision loss if I wear contact lenses. & $3.94 \pm 1.21$ & $2.95 \pm 1.29$ \\
\hline
\end{tabular}


Table 2. Comparing the perception of contact lens use between spectacle wearer and contact lens wearer

\begin{tabular}{lccccc}
\hline Variables & $\begin{array}{c}\text { Spectacle } \\
(\mathbf{n}=\mathbf{8 2}) \\
\text { Mean (SD) }\end{array}$ & $\begin{array}{c}\text { Contact Lens } \\
(\mathbf{n}=60) \\
\text { Mean }(\mathbf{S D})\end{array}$ & $\begin{array}{c}\text { Mean diff. } \\
(\mathbf{9 5 \%} \mathbf{C l})\end{array}$ & $\begin{array}{c}\text { t-stats } \\
(\mathbf{d f})\end{array}$ & $\begin{array}{c}\mathbf{P} \\
\text { value }\end{array}$ \\
\hline Perceptions in general & $3.92(0.75)$ & $2.86(0.92)$ & $1.07(0.79,1.34)$ & $7.62(140)$ & $<0.05$ \\
Costs & $3.78(0.88)$ & $3.10(1.16)$ & $0.68(0.33,1.03)$ & $3.82(105)$ & $<0.05$ \\
Complications & $4.14(0.66)$ & $3.18(1.01)$ & $0.96(0.66,1.26)$ & $6.42(95)$ & $<0.05$ \\
\hline
\end{tabular}

\subsection{Perception towards contact lens and awareness among health sciences and business management students}

Table 3 displays the mean score of responses from contact lens wearers on contact lens use. The three components studied were the reasons, concerns, and knowledge of contact lens use. The limiting movement with spectacles was the primary reason contact lens wearers from both health sciences and business management students began to wear contact lenses $(3.76 \pm 1.30$ and $3.90 \pm 1.38$, respectively). Concerning contact lens use, both groups of students felt that comfort, followed by ease of maintenance, was essential in selecting the contact lens. In terms of contact lens knowledge, both groups of students agreed that they were educated about the lifespan of contact lenses at the time of prescription. Knowledge of contact lens use had the most significant influence on students' judgments of contact lens awareness. It was followed by the concerns and reasons for using contact lenses. However, no significant differences in the perceptions towards contact lens and awareness were found among contact lens wearers from both health sciences and business management students ( $p>0.05)$ (Table 4).

Table 3. Response score for perceptions of contact lens use for contact lens wearer

\begin{tabular}{|c|c|c|}
\hline Statements & $\begin{array}{c}\mathrm{HS}^{*} \\
(\mathrm{n}=36) \\
\text { Mean } \pm \mathrm{SD} \\
\end{array}$ & $\begin{array}{c}\mathrm{BM}^{*} \\
(\mathrm{n}-42) \\
\text { Mean } \pm \mathrm{SD}\end{array}$ \\
\hline \multicolumn{3}{|l|}{ Reasons for contact lens use } \\
\hline I started wearing contact lenses because of disliked/tired of wearing spectacles. & $3.10 \pm 1.52$ & $3.40 \pm 1.52$ \\
\hline $\begin{array}{l}\text { I think physical discomfort (weight on face and headache) influences me to start wearing } \\
\text { contact lens? }\end{array}$ & $2.68 \pm 1.39$ & $3.10 \pm 1.45$ \\
\hline I started wearing contact lens due to aesthetic/visual concerns. & $3.29 \pm 1.37$ & $3.36 \pm 1.34$ \\
\hline I started wearing contact lens due to comments and suggestions from others. & $2.82 \pm 1.25$ & $3.14 \pm 1.39$ \\
\hline I started wearing contact lens due to being afraid of refractive error progression. & $2.51 \pm 1.02$ & $2.74 \pm 1.33$ \\
\hline $\begin{array}{l}\text { I started wearing contact lens due to the limitation of movement with spectacles (sports } \\
\text { and working). }\end{array}$ & $3.76 \pm 1.30$ & $3.90 \pm 1.38$ \\
\hline \multicolumn{3}{|l|}{ Concerns of contact lens use } \\
\hline Comfort is an essential aspect in choosing the type of contact lens. & $4.27 \pm 1.17$ & $4.26 \pm 1.13$ \\
\hline Price is an essential aspect in choosing the type of contact lens. & $4.00 \pm 0.94$ & $3.95 \pm 1.17$ \\
\hline Easy maintenance is essential in choosing the type of contact lens. & $4.08 \pm 0.97$ & $4.14 \pm 1.12$ \\
\hline Cosmetic is essential in choosing the type of contact lens. & $3.30 \pm 1.10$ & $3.74 \pm 1.19$ \\
\hline \multicolumn{3}{|l|}{ Knowledge of contact lens use } \\
\hline $\begin{array}{l}\text { I was informed about the possible complications of contact lens usage at the time of } \\
\text { prescription. }\end{array}$ & $4.03 \pm 0.93$ & $3.90 \pm 1.23$ \\
\hline I was informed about the lifespan of contact lenses at the time of prescription. & $4.38 \pm 0.79$ & $4.29 \pm 1.02$ \\
\hline
\end{tabular}

${ }^{*} \mathrm{HS}=$ Health Sciences, BM= Business Management

Table 4. Comparing the perception of contact lens use between Health Sciences and Business Management Students

\begin{tabular}{lccccc}
\hline Variables & $\begin{array}{c}\mathrm{HS}^{*} \\
(\mathrm{n}=36) \\
M e a n(\mathrm{SD})\end{array}$ & $\begin{array}{c}\mathrm{BM}^{*} \\
(\mathrm{n}=42) \\
M e a n(\mathrm{SD})\end{array}$ & $\begin{array}{c}\text { Mean diff. } \\
(95 \% \mathrm{Cl})\end{array}$ & $\begin{array}{c}\text { t-stats } \\
(\mathrm{df})\end{array}$ & $\begin{array}{c}\mathrm{P} \\
\text { value }\end{array}$ \\
\hline Reasons & $3.09(0.97)$ & $3.27(1.08)$ & $-0.18(-0.64,0.28)$ & $-0.77(77)$ & 0.44 \\
\hline Concerns & $3.92(0.75)$ & $4.02(0.94)$ & $-0.10(-0.49,0.29)$ & $-0.51(77)$ & 0.61 \\
\hline Knowledge & $4.20(0.80)$ & $4.10(1.04)$ & $0.11(-0.31,0.53)$ & $0.51(77)$ & 0.61 \\
\hline \multicolumn{7}{r}{${ }^{*} \mathrm{HS}=$ Health Sciences, BM= Business Management } & &
\end{tabular}

\subsection{Discussion}

This study sought to investigate the perceptions of contact lens use among health sciences and business management university students. The first part of the investigation focused on the perception of contact lenses use as an optical device which includes the general perception, cost, and complications. From the perspective of general perception, the current study discovered that spectacles wearers agreed that the use of contact lenses is difficult as opposed to contact lens wearers. The difference in perception could be explained by the fact that spectacle wearers had never tried contact lenses before and were more ease with spectacles. This finding strengthens the previous study's findings, which found that $54 \%$ of respondents reported spectacles are superior to contact lenses (Among et al., 2019). Furthermore, the participants agreed that contact lenses are harmful when compared to contact lens wearers. Meanwhile, the cost perceptions of contact lenses as an optical device revealed that spectacle wearers agreed that contact lenses were more expensive compared to contact lens wearers who had a neutral thought. This finding bolstered the previous study's findings, which found that $41.8 \%$ 
of respondents reported that contact lens is more expensive than spectacles (Kumar et al., 2017). Lack of experience with contact lenses and not knowing the exact cost of contact lenses could explain the results. Regarding complications, both groups of wearers agreed that the main issue was concerned about the infection related to contact lenses and itchiness. These findings were consistent with the study on itchy eyes that were among the top concerns among non-contact lens wearers about contact lens use (Şengör et al., 2018).

The second part of the investigation focused on the contact lens perception and awareness among contact lens wearers of health sciences and business management students that considered three perspectives: reasons for contact lens use, concerns of contact lens use and knowledge of contact lens. This study revealed no significant differences in perceptions among contact lens wearers of health sciences and business management. The main reasons reported for starting to use contact lenses were the restricted movement caused by spectacles, such as outdoor working or participating in sports. It was evidently from students of both health sciences and business management. These findings contradicted with an earlier study, which found that limitation of movement is the least preferred reason for starting to wear contact lenses. The discrepancies may be due to differences in the purpose of wearing contact lenses. Meanwhile, the control progression of refractive error was the least preferred reason for starting to wear contact lenses by contact lens wearers in both groups. The findings were similar with those of a study conducted in Turkey in 2018, with participants expressing the least reason about near vision problems and the progression of refractive errors (Şengör et al., 2018). According to participants of both health sciences and business management, comfort was the most important consideration when selecting the type of lenses. This result is corroborated with the previous study, in which $75.8 \%$ of respondents reported that comfort while wearing contact lenses was an important consideration when purchasing contact lenses.It was followed by ease of maintenance and price, with cosmetics being the least important consideration when selecting the type of contact lens respectively (Zhu et al., 2018). The knowledge of contact lens use is critical for first-time wearers as well as all contact lens wearers. Contact lens complications can be avoided by learning how to wear contact lenses correctly and carefully. According to the findings of this study, contact lens wearers from both faculties agreed that they were informed about the potential complications of contact lens use and were aware of the contact lens's lifespan. These findings indicated that contact lens wearers in both groups had contact lens knowledge and were informed about contact lens care and handling when purchasing the contact lens. The current findings agreed with a previous study which found that more than half of participants $(71.7 \%$ ) had shown sufficient knowledge about contact lens use (Among et al., 2019). This could be due to the abundance of online platforms and references via social media and awareness programmes. The findings revealed that all contact lens wearers from both health sciences and business management have similar perspectives on contact lens awareness. in which they have agreed with the same statements, presumably due to the same level of education. People with higher levels of knowledge and education tend to have the same perspective on a certain level of judgement (Alobaidan et al., 2018; Bhandari et al., 2012)

\subsection{Conclusion}

In conclusion, the perceptions of contact lens among spectacle and contact lens wearers differed in terms of contact lens in general, cost, and difficulties. Nonetheless, contact lens wearers have the same behavioural assessments of awareness regardless of their educational background. Hence, it is crucial to avoid any complications that may endanger the eye health. Proper contact lens guidelines and public knowledge, as supplied by clinicians will help to protect public health. This study did not consider the participants' refractive error, type of contact lenses, and purchasing method. A subsequent study among contact lens wearers, including these data in a survey, will aid in raising awareness of this concern. Furthermore, future research should investigate the perception of contact lens use in multiracial settings for a comprehensive approach.

\section{Acknowledgements}

We would like to thank the Faculty of Health Sciences, Universiti Teknologi MARA (UiTM), for permission to conduct this study and to all participants in this study.

\section{Paper Contribution to Related Field of Study}

This paper contributes to the behavioral science knowledge and practice of contact lens in the field of optometry. It helps in providing information regarding the perception and awareness of the contact lens wearers from different background of knowledge.

\section{References}

Alobaidan, O. S., Alkhalifah, M. K., AlSayegh, A. A., Alhumaid, F. A., Ashammery, A. S., Alghamdi, K., ... AlRashid, W. (2018). Knowledge and practice regarding contact lens among Saudi urban contact lens users. Saudi Journal of Ophthalmology, 32(2), 93-96.

Amomg,Unnikrishnan, B., \& Hussain, S. (2009). Pattern of use of contact lens among college students: a cross-sectional study in coastal Karnataka. Indian journal of ophthalmology, 57(6), 467-469.

Ayanniyi, A. A., Olatunji, F. O., Hassan, R. Y., Adekoya, B. J., Monsudi, K. F., \& Jamda, A. M. (2014). Awareness and attitude of spectacle wearers to alternatives to corrective eyeglasses. Asian Journal of Ophthalmology, 13(3), 86-94. 
Çavdarlı, C., \& Topçu-Yılmaz, P. (2018). Does long-term soft contact lens wear affect corneal and anterior chamber parameters? Turkish Journal of Ophthalmology, 48(4), 166-170.

Ch. Vijay Kumar, Y. (2013). Importance of Compliance in Contact Lens Wear -a Study to Assess the Knowledge and Practices Among Contact Lens Users for a Healthy Vision -. International Journal of Current Research and Review, 5(8), 104-109.

Gyawali, R., Nestha Mohamed, F., Bist, J., Kandel, H., Marasini, S., \& Khadka, J. (2014). Compliance and hygiene behaviour among soft contact lens wearers in the Maldives. Clinical and Experimental Optometry, 97(1), 43-47.

Ibrahim, N. K., Seraj, H., Khan, R., Baabdullah, M., \& Reda, L. (2018). Prevalence, habits, and outcomes of using contact lenses among medical students. Pakistan Journal of Medical Sciences, 34(6), 1429-1434.

Jones, L., Brennan, N. A., González-Méijome, J., Lally, J., Maldonado-Codina, C., Schmidt, T. A., ... Nichols, J. J. (2013). The TFOS International Workshop on Contact Lens Discomfort: Report of the contact lens materials, design, and care subcommittee. Investigative Ophthalmology and Visual Science, 54(11).

Neyaz, H. A., Aboauf, H. A., Kharabah, R. M., Alrasheed, S. K., Kareem, M. A., \& Zalat, M. M. (2017). Awareness of Contact Lens Wear and Care Among Female Medical Students at Taibah University, Medinah, Saudi Arabia. European Journal of Pharmaceutical and Medical Research, 4(3), 31-39.

Şengör, T., Alkibay, S., Sertoğlu, A. E., \& Kurna, S. A. (2018). Survey to determine perceptions and practices in contact lens use and identify key features of safe use education. Turkish Journal of Ophthalmology, 48(6), 288-294.

Stapleton, F., Naduvilath, T., Keay, L., Radford, C., Dart, J., Edwards, K., ... Holden, B. (2017). Risk factors and causative organisms in microbial keratitis in daily disposable contact lens wear. PloS One, 12(8), e0181343.

Tajunisah, I., Ophth, M., Reddy, S. C., \& Phuah, S. J. (2008). Knowledge and practice of contact lens wear and care among medical students of the University of Malaya. Medical Journal of Malaysia, 63(3), 207-210.

Tchiakpe, M. P., Nhyira, S. A., \& Nartey, A. (2017). Awareness and Response of Undergraduate Spectacle Wearers to Contact Lens Usage. Journal of Clinical Ophthalmology and Optometry, 1(1), 7.

Usgaonkar, U. P. S., \& Tambe, P. (2018). Awareness and Attitude Toward Refractive Error Correction Methods, Among Goan Population. Journal of Dental and Medical Sciences, 17(3), 04-10.

Venkatesh Kumar, T., Ranjee, P. H., \& Farokh, S. E. (2017). Knowledge, attitude, and practice of medical students using contact lenses. Indian Journal of Clinical and Experimental Ophthalmology, 3(3), 333

Zhu, Q., Yang, B., Deng, N., Li, Y., Wang, T., Qi, H., \& Liu, L. (2018). The use of contact lenses among university students in Chengdu: Knowledge and practice of contact lens wearers. Contact lens \& anterior eye : the journal of the British Contact Lens Association, 41(2), 229-233. 